\title{
Career Decision Ambiguity Tolerance and Career Decision- Making Difficulties in a French Sample: The Mediating Role of Career Decision Self-Efficacy
}

Journal of Career Assessment I- 16

(C) The Author(s) 2017 Reprints and permission: sagepub.com/journalsPermissions.nav DOI: $10.1177 / 1069072717748958$ journals.sagepub.com/home/jca

(SAGE

\section{Martin Storme ${ }^{1}$, Pinar Celik $^{2}$, and Nils Myszkowski ${ }^{3}$}

\begin{abstract}
In the current work, we investigated the relationship between career decision ambiguity tolerance (CDAT) and career decision-making difficulties among French-speaking university students. In a preliminary validation study $(N=246)$, we examined the psychometric properties of the CDAT Scale. Our results showed that the French CDAT Scale had satisfactory levels of scale score reliability, that its factor structure was consistent with the original three-factor structure, and that it had incremental predictive power over general ambiguity tolerance when predicting career decision self-efficacy and career adaptability. In a second study $(N=4 I 2)$, building on social cognitive career theory, we hypothesized that career decision self-efficacy mediates the relationship between CDAT and career decision-making difficulties. Results were consistent with our hypotheses. Theoretical and practical implications of the results are discussed.
\end{abstract}

\section{Keywords}

career decision ambiguity tolerance, career decision-making difficulties, career decision self-efficacy

Nowadays, individuals need to stay up-to-date on the developments in their field of work, keep an eye open for potential new opportunities, and above all make wise and timely decisions to remain employable (Betz \& Voyten, 1997; Crites, 1978; Savickas \& Porfeli, 2012). For this, individuals need to be able to collect and integrate various information about the job market and their own characteristics in relation to the job market almost on a continuous basis (Xu \& Tracey, 2015b). The information that individuals need to process is often subject to quick changes and is highly

\footnotetext{
'Université Paris Descartes, Paris, France

${ }^{2}$ Centre Emile Bernheim, Solvay Brussels School of Economics and Management, Université Libre de Bruxelles, Brussels, Belgium

${ }^{3}$ Pace University, New York City, NY, USA
}

Corresponding Author:

Martin Storme, Université Paris Descartes, Paris, Paris, France.

Email: martinstorme@ymail.com 
ambiguous, being partial, fragmented, and contradictory (Xu \& Tracey, 2014, 2015b). Researchers increasingly realize that effective career decision-making involves tolerance for the informational ambiguity in the ongoing career decision process (Xu \& Tracey, 2014, 2015b; Xu, Hou, Tracey, \& Zhang, 2016). This is the context in which the Career Decision Ambiguity Tolerance (CDAT) Scale has been elaborated (Xu \& Tracey, 2015b). Until now, there are not many studies using this scale, which warrants further study. The current work aimed to validate this scale in French (Study 1) and to test a model connecting CDAT and career decision-making difficulties (Gati, Krausz, \& Osipow, 1996), which incorporates career decision-making self-efficacy (CDSE; Betz \& Voyten, 1997) as a mediator between the two constructs (Study 2). Before introducing our theoretical model in more detail, we first describe relevant research regarding the constructs of general ambiguity tolerance, career decision-specific ambiguity tolerance, and the CDAT Scale in more detail.

\section{CDAT}

The concept of ambiguity tolerance has been an important research topic for over 60 years (Furnham, Marks, \& others, 2013). The dominant approach to ambiguity tolerance is to conceptualize the construct as a personality variable, although other researchers have also conceptualized it as a skill ( $\mathrm{Ng}, 2013)$. The most used definition describes ambiguity tolerance as the way individuals perceive, evaluate, and respond to ambiguous stimuli (Budner, 1962). According to Budner's (1962) original conceptualization of ambiguity tolerance, three sources of informational ambiguity exist to which individuals can have varying levels of tolerance: unfamiliarity, complexity, and inconsistency of information.

Recently, Xu and Tracey (2015b) worked on defining a domain-specific construct of ambiguity tolerance specifically for career decision-making - CDAT. This construct describes individuals with high levels of CDAT as comfortable and confident with career informational ambiguity while making career decisions. According to Xu and Tracey (2015b), individuals with high CDAT have a low tendency to avoid career informational ambiguity, and are interested in, and might even desire career informational ambiguity. Individuals with low levels of CDAT, on the other hand, tend to feel anxious when confronted with career informational ambiguity and try to avoid ambiguity in the career decision-making process (Xu \& Tracey, 2015b).

The career-specific approach to ambiguity tolerance echoes the reasoning of researchers who have advocated that ambiguity tolerance should be treated as a context-specific construct and that contextualized measures should be created (Herman, Stevens, Bird, Mendenhall, \& Oddou, 2010). The idea is that items used in general ambiguity tolerance measures may not be representative across different contexts. Consequently, the CDAT was defined as the way individuals deal with informational ambiguity, specifically in the process of making career decisions (Xu \& Tracey, 2015b). Xu and Tracey (2015b) found that CDAT has incremental validity beyond general ambiguity tolerance when predicting different career outcomes. This is a strong argument in favor of using a domainspecific scale when it comes to investigating the role of ambiguity tolerance in the process of making career decisions (Xu \& Tracey, 2015b).

Another reason why the CDAT is relevant relates to its factor structure. Most common general ambiguity tolerance models are unidimensional with one underlying tolerance factor theorized to stem from different sources of informational ambiguity: novelty, complexity, and inconsistency (Budner, 1962; McLain, 2009). Following this conceptualization, Xu and Tracey (2015b) initially based the construction of the CDAT largely on this tripartite model. Interestingly, however, their study revealed that students perceived ambiguity in career information according to three factors that refer to their specific reactions to informational ambiguity, instead of a general tolerance to different sources of ambiguity. These factors were preference, tolerance, and aversion for ambiguous career information. 
Preference refers to positive cognitive appraisals of ambiguous information in career decisionmaking, especially in the exploratory phase of the career decision-making process. Tolerance refers to the confidence in one's ability to cope with informational ambiguity in the career decision-making process. Finally, aversion refers to the behavioral tendency to avoid career informational ambiguity. These dimensions in short could be said to reflect the enjoyment, perceived ability, and willingness to deal with career information ambiguity, which can be considered related, yet essentially distinct concepts. Indeed, as $\mathrm{Xu}$ and Tracey (2015b) pointed out, people might be tolerant (i.e., able) to process ambiguous information in career decision-making, but they may not necessarily enjoy it, and vice versa. Similarly, people may be intrigued by ambiguous information, but at the same time they may avoid confrontation with it for various reasons - for example, because they believe ambiguity can be a threat to their future career. Supporting this reasoning, correlations between the three factors were moderate in magnitude, which means that CDAT should be considered as a multidimensional construct. This differentiation between various aspects of reactions to career informational ambiguity allows for a more fine-grained understanding of the career decision process than was previously possible with general ambiguity tolerance measures.

In a more recent study, Xu, Hou, Tracey, and Zhang (2016) found that the original three-factor structure of CDAT - as observed in an American college sample (Xu \& Tracey, 2015b) — was not adequate in the Chinese population. In the Chinese population, it appeared that only the Preference and Aversion subscales of the CDAT were meaningful factors. Xu et al. (2016) suggested to drop the tolerance factor when using the CDAT in Chinese samples and speculated that the differential structural patterns of tolerance across China and the United States may have resulted from different cultural values. Following the same reasoning, the structure of CDAT could also be different in France. France is indeed more uncertainty avoidant compared to China and the United States (G. H. Hofstede \& Hofstede, 2001). A higher level of uncertainty avoidance in the population could result in more extreme scores on CDAT, with possible floor effects on tolerance and preference and ceiling effects on aversion. Floor and ceiling effects can jeopardize traditional factor analysis and provide inappropriate factor solutions (see, Muthen \& Kaplan, 1992). Consequently, testing the factor structure of CDAT and replicating the initial validation study conducted by $\mathrm{Xu}$ and Tracey (2015b) in a French sample is a first aim of our current work.

\section{Theoretical Model}

A second aim of our current work is to investigate a theoretical model that links CDAT to career decision-making difficulties. In doing so, a conceptual validation of CDAT is provided, as well as a theoretical contribution to the understanding of the career decision process. Echoing the ongoing developments on the job market, various theoretical approaches, such as social cognitive career theory (SCCT, Lent et al., 1994; Lent \& Brown, 2013), recognize and emphasize the importance of an active and dynamic attitude when managing one's own career. Applied to career decisionmaking, SCCT would predict that effective career decision-making depends on a complex combination of general abilities and values, concrete career decision-making skills, contextual factors, and cognitive motivational processes related to career decision-making. The present work aimed to test a mediation model based on SCCT that frames CDAT as an essential cognitive motivational and ability construct relevant for understanding career decision-making. The model that we propose conceives of CDAT as a predictor of both CDSE (Betz \& Voyten, 1997) and career decision-making difficulties, as measured by the Career Decision-Making Difficulties Questionnaire (CDDQ; Gati et al., 1996).

Career decision-making difficulties. Gati, Krausz, and Osipow (1996) offered taxonomy of the subjective experience of career decision-making difficulties, which is still regularly used in recent research 
on careers (e.g., Xu \& Tracey, 2015a; Storme \& Celik, 2017). Career decision-making difficulty in this taxonomy is a multidimensional construct that takes into account three overarching dimensions: lack of readiness (LR), lack of information (LI), and inconsistent information (II). Within this taxonomy, LR consists of a lack of willingness to make a decision, a general trait-like indecisiveness, and dysfunctional beliefs - that is, unrealistic expectations regarding one's future career. LI consists of four indicators, relating to information about one's self, about occupations, and about how to obtain further information. Finally, II consists of unreliable information, internal conflicts, and external conflicts.

Previous studies found negative correlations between general ambiguity tolerance and career decision-making difficulties measured with the CDDQ (Gati et al., 1996). Xu and Tracey (2014, 2015a) found that LR, LI, and II were negatively correlated with the Preference and Tolerance subscales of the CDAT (coefficients ranged between -.32 and -.24) and positively correlated with the aversion dimension of the CDAT (coefficients ranged from .46 to .60). When the subscales of CDAT were entered simultaneously in one regression model, tolerance appeared systematically nonpredictive for all subdimensions of the CDDQ (Xu \& Tracey, 2015a).

CDSE. The concept of self-efficacy originated from social cognitive theory (Bandura, 1977). It refers to feelings of mastery and confidence that one can achieve one's goals in life (Bandura, 1977). Selfefficacy is partly the result of previous learning experiences and partly of individuals' subjective appraisal of these experiences (Bandura, 1977; Lent \& Brown, 2013; Lent et al., 1994). In the domain of career decision-making, Betz, Klein, and Taylor (1996) proposed the concept of CDSE and developed the CDSE-Short Form (CDSE-SF) Scale (Betz, Klein, \& Taylor, 1996). Career decision self-efficacy is defined as an individual's confidence in his/her ability to complete the tasks that are required to make career decisions. Five subdimensions of self-efficacy were identified as critical for CDSE, based on the work of Crites (1978) describing core activities contributing to making efficient career decisions: the accurate appraisal of one's job-related capabilities, understanding the world of work, matching one's personal characteristics to job requirements, planning one's career path, and coping with problems related to career decisions.

In SCCT (Lent et al., 1994; Lent \& Brown, 2013), career decision self-efficacy can be conceptualized as an important cognitive motivational antecedent of career decision-making. Previous research has reported negative correlations between CDSE and different measures of career decision-making difficulties (Choi et al., 2012; Osipow \& Gati, 1998; Xu \& Tracey, 2015a, 2015b). In sum, individuals who have confidence in their ability to engage in career decisionrelated activities are expected to be more motivated to make a career decision, the information about the why's and wherefore's of their options, and to be less likely to durably consider that available career or self-information is insufficient or inconsistent.

According to SCCT, previous social learning experiences are at the basis of CDSE (Lent \& Brown, 2013; Xu \& Tracey, 2015a). Xu and Tracey (2015a) argued that individuals with low CDAT tend to experience more negative experiences while making career decisions because of their difficulty to solve problems that require managing complex information. Such negative experiences in turn feed negative beliefs and lower one's confidence in one's ability to make career decisions (Xu \& Tracey, 2015a). Based on this, we argue that ambiguity tolerance should be a predictor of CDSE. Indeed, Xu and Tracey (2015b) found in their initial validation of the CDAT that the construct is related to CDSE, as measured by the CDSE-SF (Betz et al., 1996). Bivariate correlations indicated that career decision self-efficacy was positively associated with the tolerance $(r=.41)$ and preference $(r=.25)$ subscales of the CDAT and negatively associated with aversion $(r=-.39)$. When the subscales of CDAT were entered simultaneously in one regression model, preference appeared nonpredictive for career decision self-efficacy. 
Mediation model. As mentioned above, $\mathrm{Xu}$ and Tracey (2015b) found that CDAT predicts both CDSE - measured with the CDSE-SF (Betz et al., 1996) - and career decision-making difficulties-measured with the CDDQ (Gati et al., 1996). However, Xu and Tracey (2015b) did not investigate the joint effects of CDAT and career decision self-efficacy in predicting career decision-making difficulties nor the potential mediating role of career decision self-efficacy. The only previous study that investigated directly the interrelations between ambiguity tolerance, CDSE, and career decision-making difficulties used a nonspecific and unidimensional measure of ambiguity tolerance (Xu \& Tracey, 2015a). This study found that CDSE mediated the relationship between general ambiguity tolerance and career decision-making difficulties. The model that we propose states that CDAT plays an important role in the social learning experiences that in turn form career decision self-efficacy beliefs, which then influences the difficulties that individuals experience when in the process of making career decisions.

\section{Study Overview}

In Study 1, we investigate the internal consistency, factor structure, convergent validity, and incremental validity of the CDAT among French-speaking undergraduate students. Regarding the factor structure, we test using confirmatory factor analyses (CFA) whether the original three-factor model (Xu \& Tracey, 2015b) is adequate in the French population. We investigate the criterion and incremental validity of the French CDAT by replicating observed correlations obtained with the original English version. In this first study, we also test whether CDAT has incremental validity over general ambiguity tolerance when predicting career decision self-efficacy and career adapt-abilities.

In Study 2, we test a mediation model incorporating the idea that being tolerant for career information ambiguity predicts a sense of mastery and self-efficacy in the career decision process as assessed with the CDSE-SF (Betz et al., 1996), the latter indicating a key cognitive motivational resource in career decision-making. This in turn should predict individuals' experiences of difficulties in the career decision-making process, as measured with the CDDQ (Gati et al., 1996). We hypothesize that the CDAT dimensions preference and tolerance are positively related to career decision self-efficacy and negatively related to all three dimensions of career decisionmaking difficulties. In addition, we hypothesize that the CDAT dimension aversion is negatively related to career decision self-efficacy and positively to all three dimensions of career decisionmaking difficulties.

Previous studies found that CDSE seems more strongly associated with difficulties related to information processing (i.e., LI and II), than with LR (Osipow \& Gati, 1998; Xu \& Tracey, 2015a, 2015b). Based on these findings, we hypothesize that CDSE negatively predicts difficulties pertaining to LI and II and does not predict difficulties pertaining to LR. Consequently, career decision selfefficacy mediates the relationship between CDAT and career decision-making difficulties, specifically on the subdimensions LI and II.

\section{Study I: Validation of the CDAT in French}

The aim of the first study was to investigate the internal consistency, the factor structure, the criterion validity, and the incremental validity of the French CDAT Scale. Regarding the factor structure, the original three-factor model - preference, tolerance, and aversion-was tested.

In the original validation, $\mathrm{Xu}$ and Tracey (2015b) also investigated correlates of CDAT. Notably, they found correlations with general ambiguity tolerance, CDSE, and career adapt-abilities. Moreover, they found that CDAT predicts CDSE (Betz et al., 1996) and career adapt-abilities (Savickas \& Porfeli, 2012) beyond general ambiguity tolerance (McLain, 2009). The aim of the first study was to replicate those findings with a French version of the CDAT Scale. 


\section{Method}

\section{Participants}

The sample consisted of 246 French undergraduate students in their first year of business administration studies $\left(M_{\mathrm{age}}=18.36, S D_{\mathrm{age}}=0.85\right.$, range $18-23$ years). In the sample, $51.63 \%$ of the participants were male $(n=127)$ and $48.37 \%$ were female $(n=119)$. Because in France it is illegal to collect information about participants' ethnicity, we have no information about participants' ethnic backgrounds. Participants were invited to participate voluntarily to the survey as part of a course on human resources management. Over $95 \%$ of students enrolled in the course participated in the survey.

\section{Measurement}

CDAT. The CDAT Scale is an 18-item self-report questionnaire (Xu \& Tracey, 2015b). It assesses individuals' perceptions of complex, original, inconsistent, and unpredictable information during the process of making a career decision. The scale consists of three subscales: preference (6 items), tolerance (6 items), and aversion (6 items). Participants respond to the questionnaire using a 5-point Likert-type scale from 1 (strongly disagree) to 5 (strongly agree). Two French native speakers translated the 18 original items into French and an independent English native speaker then translated them back into English for validation purposes. Minor differences in translation were discussed and all translators agreed on a final version of the French scale. In previous studies, the scale was found to have satisfactory structural and construct validity, being correlated with CDSE (Xu \& Tracey, 2015b), career adapt-abilities (Xu \& Tracey, 2015b), career exploration (Xu et al., 2016), and also with emotional and personality-related career difficulties (Xu et al., 2016). In the current sample, the scale showed satisfactory internal consistency with Cronbach's $\alpha$ being $.80, .77$, and .78 for preference, tolerance, and aversion, respectively. The French version of the CDAT is available from the corresponding author upon request.

Multiple Stimulus Types Ambiguity Tolerance Scale II (MSTAT-II). To assess the level of general ambiguity tolerance of participants, we used the French version of the MSTAT-II (McLain, 2009), which has been shown to have satisfactory psychometric properties and was used in the initial validation of the CDAT Scale. In previous empirical studies, the MSTAT-II was found to correlate with other validated measures of general ambiguity tolerance (McLain, 2009) but also with CDAT (Xu \& Tracey, 2015b). Participants respond using a 5-point Likert-type scale from 1 (strongly disagree) to 5 (strongly agree). The observed internal consistency in our sample was satisfactory (Cronbach's $\alpha=.80)$.

CDSE-SF. We used the French version of the 25-item CDSE-SF (Betz et al., 1996; Gaudron, 2013) to measure students' self-efficacy regarding making career decisions in five domains: accurate selfappraisal (5 items), gathering occupational information (5 items), goal selection (5 items), making plans for the future (5 items), and problem-solving ( 5 items). Responses were given on a 5-point Likert-type scale ranging from 1 (no confidence at all) to 5 (complete confidence). Previous empirical research has shown that this scale has satisfactory psychometric properties with an overall Cronbach's $\alpha$ of .94. The scale also had satisfactory psychometric properties in our sample (Cronbach's $\alpha$ was .90). Previous research has shown that the CDSE-SF is negatively associated with career decision-making difficulties (Osipow \& Gati, 1998; Xu \& Tracey, 2015b) and positively associated with career adapt-abilities (Xu \& Tracey, 2015b). Xu and Tracey (2015b) found that the CDSE-SF was positively correlated with the preference and tolerance dimensions of CDAT and negatively correlated with the aversion dimension of CDAT (Xu \& Tracey, 2015b). 
Career Adapt-Abilities Scale (CAAS). We assessed career adaptability with the CAAS (Savickas \& Porfeli, 2012; Johnston et al., 2013). The scale measures four dimensions of career adaptability: concern (6 items), control (6 items), curiosity (6 items), and confidence (6 items). Five-point Likerttype scales ranging from 1 (not strong) to 5 (strongest) were used. The original CAAS has been shown to have satisfactory psychometric properties (Cronbach's $\alpha$ between .74 and .85 across subscales) and construct validity (Savickas \& Porfeli, 2012). In our sample, the subscales also exhibited satisfactory scale score reliability (Cronbach's $\alpha$ for concern, control, curiosity, and confidence were $.82, .80, .79$, and .82 , respectively).

\section{Procedure}

Students were invited to participate in this study as part of a course. Participants filled in all questionnaires online and anonymity and confidentiality were guaranteed. The online survey was programmed in a way that it was required from participants that they answered all items before they could submit their responses. As a consequence, we had no missing data.

\section{Analysis}

CFA were conducted using the lavaan package in R (Rosseel, 2012). To model CDAT, we used the items of the scales as indicators. Regarding absolute model fit, we followed the recommendations of Schumacker and Lomax (2004) and used four statistical indices: the $\chi^{2} / d f$ ratio (should be less than 3), the comparative fit index (CFI should be more than .90), the standardized root mean square residual (SRMR should be less than .08), and the root mean square error of approximation (RMSEA should be less than .08). Model comparisons were based on the minimum Akaike information criterion (AIC) procedure (Burnham \& Anderson, 2002). According to this procedure, the preferred model should be the one with the lowest AIC. We report standardized model coefficients.

\section{Results}

\section{Univariate and Bivariate Statistics}

Univariate and bivariate statistics are reported in Table 1. General ambiguity tolerance appeared positively correlated with preference $(r=.17, p<.01)$ and tolerance $(r=.35, p<.01)$ and negatively correlated with aversion $(r=-.44, p<.01)$. CDSE also appeared positively correlated with preference $(r=.28, p<.01)$ and tolerance $(r=.34, p<.01)$ and negatively correlated with aversion $(r=-.30, p<.01)$. Finally, the four dimensions of career adaptability were positively correlated with preference and tolerance and negatively correlated with aversion (see Table 1). These results are in line with our expectations regarding the criterion validity of the CDAT.

\section{Factor Structure}

CFA were conducted to investigate the factor structure of the CDAT. The theoretical model that was tested for the CDAT was a model with three correlated factors (preference, tolerance, and aversion). The fit of the theoretical model was also compared with the fit of a unidimensional model and with the fit of a model with three independent factors (preference, tolerance, and aversion).

According to the minimal AIC procedure, the three-correlated factor model $\left(\chi^{2} / d f=199.86 /\right.$ $132=1.51, \mathrm{CFI}=.95, \mathrm{AIC}=9,372.80, \mathrm{RMSEA}=.04, \mathrm{SRMR}=.05)$ was found to fit the data 
Table I. Study I: Descriptive Statistics.

\begin{tabular}{lcccccccccc}
\hline & Mean & SD & 1 & 2 & 3 & 4 & 5 & 6 & 7 & 8 \\
\hline I. CDAT_Preference & 4.30 & 0.44 & - & & & & & & & \\
2. CDAT_Tolerance & 3.74 & 0.51 & 0.40 & - & & & & & & \\
3. CDAT_Aversion & 2.64 & 0.58 & -0.16 & -0.48 & - & & & & & \\
4. AT & 3.07 & 0.53 & 0.17 & 0.35 & -0.44 & - & & & & \\
5. CDSE-SF & 3.63 & 0.42 & 0.28 & 0.34 & -0.30 & 0.23 & - & & & \\
6. CAAS-Concern & 3.68 & 0.62 & 0.21 & 0.33 & -0.33 & 0.25 & 0.61 & - & & \\
7. CAAS-Control & 3.92 & 0.63 & 0.20 & 0.28 & -0.23 & 0.22 & 0.56 & 0.51 & - & \\
8. CAAS-Curiosity & 3.74 & 0.59 & 0.24 & 0.28 & -0.22 & 0.26 & 0.55 & 0.52 & 0.52 & \\
9. CAAS-Confidence & 3.96 & 0.56 & 0.27 & 0.29 & -0.28 & 0.24 & 0.62 & 0.48 & 0.66 & 0.52 \\
\hline
\end{tabular}

Note. $N=246 .|r|>.13$ are significant at $p=.05 .|r|>.17$ are significant at $p=.01$. CDAT = Career Decision Ambiguity Tolerance; MSTAT-II = Multiple Stimulus Types Ambiguity Tolerance Scale II; CDSE-SF = Career Decision Self-EfficacyShort Form; CAAS = Career Adapt-Abilities Scale; AT = Ambiguity Tolerance measured by the Multiple Stimulus Types Ambiguity Tolerance Scale II.

better than the unidimensional model $\left(\chi^{2} / d f=622.82 / 135=4.61, \mathrm{CFI}=.61, \mathrm{AIC}=9789.76\right.$, $\mathrm{RMSEA}=.12, \mathrm{SRMR}=.11)$ and the three-independent factor model $\left(\chi^{2} / d f=298.94 / 135=2.21\right.$, $\mathrm{CFI}=.87, \mathrm{AIC}=9,465.88, \mathrm{RMSEA}=.07, \mathrm{SRMR}=.14)$. The observed fit indices suggest that the three-correlated factor model has an acceptable fit. This result is in line with our expectations regarding the factor structure of the CDAT. Estimates of the three-correlated factor model are reported in Table 2.

\section{Incremental Validity}

In Table 3, we report the results of stepwise regressions conducted to investigate the incremental validity of the CDAT on CDSE and career adapt-abilities. We found that the CDAT has increased predictive value for CDSE, $F(3,241)=11.42, p<.01$; career adaptability-concern $F(3,241)=10.08, p<$ .01 ; career adaptability-control $F(3,241)=5.70, p<.01$; career adaptability-curiosity: $F(3,241)=5.61$, $p<.01$; and career adaptability-confidence $F(3,241)=8.31, p<.01$; beyond general ambiguity tolerance.

\section{Discussion}

The aim of the first study was to investigate the internal consistency, the factor structure, the criterion validity, and the incremental validity of CDAT in a sample of French students. We found satisfactory levels of scale score reliability for the three subscales of the French CDAT Scale. The original three-factor structure was replicated with the French CDAT Scale. Finally, this first study also replicated the incremental validity of CDAT beyond general ambiguity tolerance when predicting career decision self-efficacy and career adapt-abilities. Altogether, these preliminary results are promising.

\section{Study 2: Mediation Study}

CDAT is especially relevant as a predictor of career decision-making difficulties (Xu \& Tracey, 2014, 2015a, 2015b). This can be understood from the perspective of SCCT (Lent \& Brown, 2013; Lent et al., 1994). Seen from the lens of SCCT, individuals who enjoy, are able, and willing to deal with career information ambiguity should be more confident regarding their ability to engage in career decision-related activities. This is because engaging in 
Table 2. Study I: Factor Loadings of the French CDAT.

\begin{tabular}{|c|c|c|c|}
\hline Item & Preference & Tolerance & Aversion \\
\hline $\begin{array}{l}\text { I am interested in exploring the many aspects of my personality and } \\
\text { interests }\end{array}$ & 0.73 & & \\
\hline $\begin{array}{l}\text { I am excited that I can learn new things about myself or about the world } \\
\text { when making a career decision }\end{array}$ & 0.76 & & \\
\hline I am excited to see a creative way to match my interests with a career & 0.60 & & \\
\hline It is interesting to discover new strengths and weaknesses & 0.64 & & \\
\hline I am not interested in knowing new information about myself & 0.65 & & \\
\hline I am open to careers which I have never heard of or thought of before & 0.46 & & \\
\hline I enjoy tackling complex career decision-making tasks & & 0.56 & \\
\hline $\begin{array}{l}\text { I am tolerant of the potential difference between my perception and the } \\
\text { reality of a career }\end{array}$ & & 0.59 & \\
\hline I am able to make a choice when multiple options seem equally appealing & & 0.50 & \\
\hline I am tolerant of the unpredictability of a career & & 0.64 & \\
\hline I am tolerant with the possibility that my interests could change in the future & & 0.70 & \\
\hline I do not mind changing my career in the future if necessary & & 0.59 & \\
\hline I try to avoid complicated career decision-making tasks & & & 0.63 \\
\hline I find it difficult to make career decision as things cannot be predicted clearly & & & 0.62 \\
\hline I am afraid of sorting out the complex aspects of a career & & & 0,68 \\
\hline $\begin{array}{l}\text { The career decision-making process, which involves so many } \\
\text { considerations, is just daunting }\end{array}$ & & & 0.62 \\
\hline I try to avoid a career in which the prospects cannot be foreseen clearly & & & 0.57 \\
\hline $\begin{array}{l}\text { People's different or sometimes contradictory perspectives about a career } \\
\text { makes me uncomfortable }\end{array}$ & & & 0.54 \\
\hline Mean & 4.30 & 3.74 & 2.64 \\
\hline Standard deviation & 0.44 & 0.51 & 0.58 \\
\hline Cronbach's $\alpha$ & 0.80 & 0.77 & 0.78 \\
\hline Factor correlation preference & - & 0.48 & -0.23 \\
\hline Factor correlation tolerance & & - & -0.58 \\
\hline
\end{tabular}

Note. $N=246$. All estimates are significant at $p=.0 \mathrm{I} . \mathrm{CDAT}=$ Career Decision Ambiguity Tolerance.

such activities requires the motivation and ability to deal with career information ambiguity. Consequently, significant correlations should be observed between CDAT and CDSE, the latter in turn mediating the relationship between CDAT and career decision-making difficulties.

Supporting the predictions derived from SCCT, previous research has shown that CDAT, career decision self-efficacy, and career decision-making difficulties are correlated (Xu \& Tracey, 2015b). To extend these findings, we test a model in which CDSE mediates the relationship between CDAT and career decision-making difficulties.

\section{Method}

\section{Participants}

French third-year business administration students $(N=412)$ participated in the second study $\left(M_{\text {age }}=20.77, S D_{\text {age }}=1.18\right.$, range: $19-35$ years $)$. In the sample, $42.48 \%$ of the participants were male $(n=175)$ and $57.52 \%$ were female $(n=237)$. As in Study 1, participants were invited to participate voluntarily to the survey as part of a course on human resources management. More than $95 \%$ of all students enrolled in the course participated in the survey. 
Table 3. Study I: Stepwise Regression Results.

\begin{tabular}{|c|c|c|c|c|c|c|}
\hline Step & Variable & $B$ & SE & $\beta$ & $R^{2}$ & Delta $F$ \\
\hline \multicolumn{7}{|l|}{ CDSE-SF } \\
\hline Step I & AT & 0.18 & 0.05 & $0.23^{* *}$ & .05 & $F(I, 244)=13.21, p<.01$ \\
\hline \multirow[t]{4}{*}{ Step 2} & AT & 0.05 & 0.05 & 0.07 & .17 & $F(3,24 I)=1 I .42, p<.01$ \\
\hline & Preference & 0.17 & 0.06 & $0.17 * *$ & & \\
\hline & Tolerance & 0.14 & 0.06 & $0.16^{*}$ & & \\
\hline & Aversion & -0.12 & 0.05 & $-0.17^{*}$ & & \\
\hline \multicolumn{7}{|c|}{ CAAS-Concern } \\
\hline Step I & AT & 0.29 & 0.07 & $0.25 * *$ & .06 & $F(I, 244)=15.79, p<.01$ \\
\hline \multirow[t]{4}{*}{ Step 2} & AT & 0.10 & 0.07 & 0.08 & .17 & $F(3,24 I)=10.08, p<.01$ \\
\hline & Preference & 0.14 & 0.09 & 0.10 & & \\
\hline & Tolerance & 0.21 & 0.09 & $0.17^{*}$ & & \\
\hline & Aversion & -0.22 & 0.08 & $-0.20 * *$ & & \\
\hline \multicolumn{7}{|c|}{ CAAS-Control } \\
\hline Step I & AT & 0.26 & 0.07 & $0.22 * *$ & .05 & $F(I, 244)=11.86, p<.01$ \\
\hline \multirow[t]{4}{*}{ Step 2} & AT & 0.12 & 0.08 & 0.10 & .11 & $F(3,24 I)=5.70, p<.0 \mathrm{I}$ \\
\hline & Preference & 0.14 & 0.10 & 0.10 & & \\
\hline & Tolerance & 0.21 & 0.09 & $0.16^{*}$ & & \\
\hline & Aversion & -0.19 & 0.08 & -0.10 & & \\
\hline \multicolumn{7}{|c|}{ CAAS-Curiosity } \\
\hline Step I & AT & 0.30 & 0.07 & $0.26 * *$ & .07 & $F(I, 244)=18.04, p<.01$ \\
\hline \multirow[t]{4}{*}{ Step 2} & AT & 0.18 & 0.08 & $0.16^{*}$ & .13 & $F(3,24 I)=5.6 I, p<.0 I$ \\
\hline & Preference & 0.19 & 0.09 & $0.14 *$ & & \\
\hline & Tolerance & 0.16 & 0.09 & 0.14 & & \\
\hline & Aversion & -0.06 & 0.07 & -0.06 & & \\
\hline \multicolumn{7}{|c|}{ CAAS-Confidence } \\
\hline Step I & AT & 0.25 & 0.07 & $0.24 * *$ & .06 & $F(I, 244)=14.50, p<.01$ \\
\hline \multirow[t]{4}{*}{ Step 2} & AT & 0.11 & 0.07 & 0.10 & .15 & $F(3,24 I)=8.3 I, p<.0 I$ \\
\hline & Preference & 0.23 & 0.08 & $0.18^{* *}$ & & \\
\hline & Tolerance & 0.11 & 0.08 & 0.10 & & \\
\hline & Aversion & -0.15 & 0.07 & $-0.15^{*}$ & & \\
\hline
\end{tabular}

Note. $N=246$. MSTAT-II = Multiple Stimulus Types Ambiguity Tolerance Scale II; CDSE-SF = Career Decision Self-EfficacyShort Form; CAAS = Career Adapt-Abilities Scale; AT = Ambiguity Tolerance measured by the Multiple Stimulus Types Ambiguity Tolerance Scale II.

$*_{p}<.05 . * * p<.01$.

\section{Measurement}

CDAT. We used the same scale as in Study 1. Again in this study, the scale showed satisfactory scale score reliability. Cronbach's $\alpha$ were .78, .70, and .73 for preference, tolerance, and aversion, respectively.

CDSE-SF. We used the same scale as in Study 1. The scale also had satisfactory psychometric properties in the current sample (Cronbach's $\alpha$ was .91).

CDDQ. The CDDQ (Gati et al., 1996; Massoudi, Masdonati, Clot-Siegrist, Franz, \& Rossier, 2008) assesses 10 dimensions of career indecision (Gati et al., 1996): lack of motivation (LM, 3 items), general indecisiveness (GI, 3 items), dysfunctional beliefs (DBs, 4 items), LI regarding the stages of the career decision-making process (LP, 3 items), LI regarding the self(LS, 4 items), LI regarding occupations (LO, 3 items), lack of additional information (LA, 2 items), unreliable information (IU, 3 items), internal conflicts (INs, 5 items), and external conflicts (IEs, 2 items). 
Table 4. Study 2: Descriptive Statistics.

\begin{tabular}{lcccccccc}
\hline & Mean & SD & \multicolumn{1}{c}{1} & 2 & 3 & 4 & 5 & 6 \\
\hline I. CDAT_Preference & 3.94 & 0.59 & - & & & & & \\
2. CDAT_-Tolerance & 3.48 & 0.48 & 0.29 & - & & & & \\
3. CDAT_Aversion & 3.11 & 0.54 & -0.11 & -0.11 & - & & & \\
4. CDSE-SF & 3.57 & 0.46 & 0.27 & 0.29 & -0.16 & - & & \\
5. CDDQ-Lack of readiness & 4.76 & 1.24 & -0.19 & -0.17 & 0.30 & -0.24 & - & \\
6. CDDQ_Lack of information & 4.49 & 1.63 & -0.18 & -0.10 & 0.35 & -0.32 & 0.65 & - \\
7. CDDQ_-Inconsistent information & 4.08 & 1.58 & -0.24 & -0.10 & 0.29 & -0.28 & 0.62 & 0.78
\end{tabular}

Note. $N=412 .|r|>.10$ are significant at $p=.05 .|r|>.13$ are significant at $p=.01$. CDAT = Career Decision Ambiguity Tolerance; CDSE-SF = Career Decision Self-Efficacy—Short Form; CDDQ = Career Decision-Making Difficulties Questionnaire.

The model distinguishes three second-order factors: $L R$ - which is extracted from LM, GI, and DBs; $L I$ - which is extracted from LP, LS, LO, and LA; and II-which is extracted from IU, INs, and IEs.

Participants respond using 9-point Likert-type scales ranging from 1 (does not describe me) to 9 (describes me well). The CDDQ has been shown to have satisfactory psychometric properties (Cronbach's $\alpha$ ranging between .70 and .90) and construct validity (Willner, Gati, \& Guan, 2015). The subscales showed satisfactory scale score reliability in our sample (Cronbach's $\alpha$ for LR, LI, and II were .73, .94, and .90, respectively).

\section{Procedure}

We invited students to participate in this study as part of a course. Participants filled in all questionnaires online and anonymity and confidentiality were guaranteed. As in Study 1, the online survey was programmed in a way that it was required from participants that they answered all items before they could submit their responses. As a consequence, we had no missing data.

We asked students to think about the difficulties they experienced during the process of choosing their master specialization when filling in the CDDQ. Indeed, in the European Union, the first 3 years of business administration university are general and students have to choose their master specialization (marketing, finance, etc.) during the third year of their education. Such a decision is not necessarily easy to make because there are many things to take into account such as the academic difficulty of the chosen track, personal preferences for specific topics, the job market, and so on.

\section{Analysis}

Measurement and structural models were tested within the framework of structural equation modeling (SEM, Schreiber, Nora, Stage, Barlow, \& King, 2006) and we used the lavaan package in R (Rosseel, 2012) to perform the analyses. SEM is a more precise test compared to using simple sum scores because it corrects for unreliability of the measurements (Byrne, 2013). Thresholds for fit indices were the same as in Study 1. To model CDAT, we used the items of the scales as indicators. For CDSE Scale and CDDQ, we used the sum scores of the subscales as indicator variables of latent variables.

\section{Results}

\section{Univariate and Bivariate Statistics}

Univariate and bivariate statistics are reported in Table 4. Consistent with Study 1, career decision self-efficacy appeared positively correlated with preference $(r=.27, p<.01)$ and tolerance $(r=.29$, 


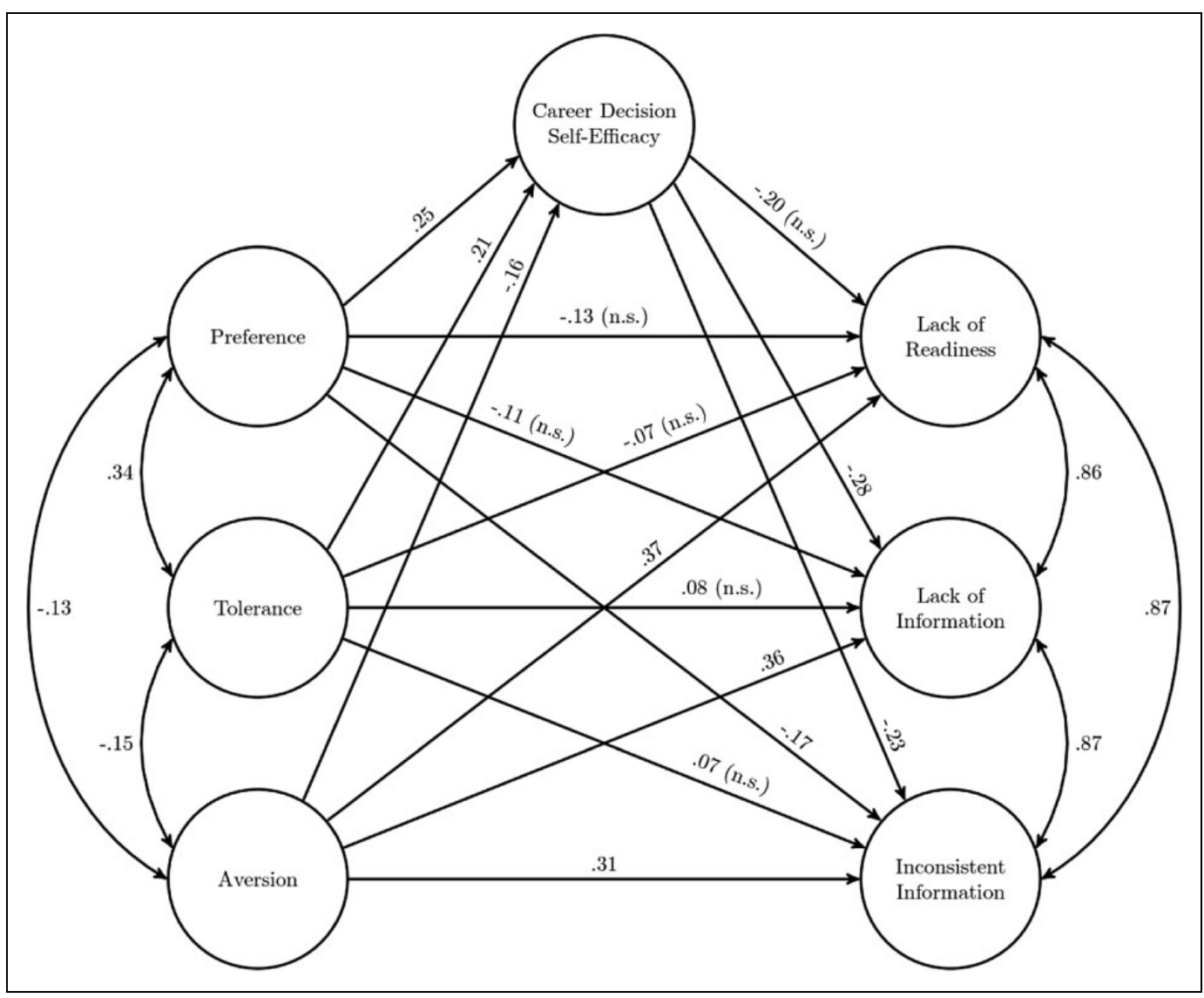

Figure I. Standardized estimates of the model. All estimates are significant, except when indicated with n.s.

$p<.01)$ and negatively correlated with aversion $(r=-.16, p<.01)$. Consistent with our expectations, LR, LI, and II were negatively correlated with preference and tolerance and positively correlated with aversion (see Table 4).

\section{Mediation Analyses}

We first tested the measurement model before assessing the structural relationships. The measurement model showed satisfactory fit $\left(\chi^{2} / d f=1,014.63 / 474=2.14, \mathrm{CFI}=.91\right.$, SRMR $=.06$, RMSEA $=.05)$. The data supported our theoretical expectations regarding the factor structure of CDAT, CDSE, and career decision-making difficulties.

We then assessed the structural relationships to test our mediation hypotheses. A simplified version of the model —including only the paths between latent variables — can be found in Figure 1. Preference was found to have a marginally significant total effect on $\operatorname{LR}(B=-0.32, p=.05)$. Preference also had a significant total effect on $\mathrm{LI}(B=-0.40, p<.01)$ and II $(B=-0.52, p<.01)$. Career decision self-efficacy mediated the effect of preference on LI, $B=-0.16, p<.01,95 \% \mathrm{CI}=[-0.27,-0.04]$, and II, $B=-0.13$, $p<.01,95 \% \mathrm{CI}=[-0.23,-0.03]$. Aversion had a significant total effect on $\operatorname{LR}(B=0.95, p<.01), \mathrm{LI}(B$ $=1.23, p<.01)$, and II $(B=1.08, p<.01)$. CDSE mediated the effect of aversion on LI, $B=0.14, p<.05$, $95 \% \mathrm{CI}=[0.01,0.27]$, and II, $B=0.12, p<.05,95 \% \mathrm{CI}=[0.01,0.23]$. Tolerance was found to have no total effect on career decision-making difficulties when controlling for preference and aversion. 


\section{Discussion}

Our findings are in line with the mediation model inspired from SCCT. We found that especially preference and aversion have significant total effects on LR, LI, and II. Career decision self-efficacy was found to mediate the effects of aversion on LI and II. We also found that career decision selfefficacy mediated the effects of preference on LI and II. Our findings replicate and extend previous research (Xu \& Tracey, 2015a) by showing that the relationship between CDAT and career decisionmaking difficulties is mediated by CDSE.

\section{General Discussion}

The current research had the aim to validate the CDAT (Xu \& Tracey, 2015b) in French and to test a model of the relationship between CDAT and career decision-making difficulties (Gati et al., 1996) in a French sample of young students. The model described CDAT as a predictor of career decisionmaking difficulties, through the mediating role of CDSE (Betz \& Voyten, 1997). Overall, the two studies conducted provided favorable results. Below, we first review the results of the validation study and then turn to the second study which tested the theoretical model.

Overall, Study 1 showed that the French CDAT has satisfactory psychometric properties. First, regarding the internal consistency, we found satisfactory levels of scale score reliability for all three subscales of the French CDAT Scale. The observed Cronbach's $\alpha$ s were comparable to those obtained in the original validation by $\mathrm{Xu}$ and Tracey (2015b).

Second, regarding the factor structure, analyses showed that it is consistent with the original three-factor structure found in two previous studies (Xu \& Tracey, 2015b; Xu, Hou, Tracey, \& Zhang, 2016). As in the original version, the three factors of the French CDAT are preference, tolerance, and aversion. Correlations between the three factors were found to be moderate in magnitude, meaning that CDAT should be considered as a multidimensional construct.

Third, regarding the criterion validity, the French CDAT was, as predicted, associated with CDSE (Betz \& Voyten, 1997) and career adaptability (Savickas \& Porfeli, 2012) - as measured respectively with the CDSE-SF (Betz \& Voyten, 1997) and the CAAS (Savickas \& Porfeli, 2012). Moreover, the predictive value of the CDAT for these constructs went beyond that of general ambiguity tolerance - measured with the MSTAT-II (McLain, 1993) - demonstrating the incremental validity of CDAT, as in the original validation study.

Finally, an important contribution to the existing literature is that, in Study 2, we found relationships between CDAT and career decision-making difficulties that were consistent with the results obtained by $\mathrm{Xu}$ and Tracey $(2015 \mathrm{~b})$. We found that the preference and aversion dimensions of CDAT had significant total effects on LR, LI, and II . Regarding the tolerance dimension-despite significant bivariate correlations with all outcome variables in the model-we found that in the regression model including all three dimensions of CDAT, the contribution of tolerance became nonsignificant. This finding is also consistent with previous studies that only reported significant bivariate correlations for the tolerance dimension, but no significant contribution when controlling for preference and aversion (Xu \& Tracey, 2015b).

As an important extension of the previous literature, we also found in our second study that CDSE mediated (1) the effects of aversion on LI and II and (2) the effects of preference on LI and II. From the perspective of SCCT, CDAT can be seen as an antecedent of career decision self-efficacy. In other words, individuals with low levels of CDAT tend to feel less confident when engaging in career decision-related activities, which can explain partly why they experience difficulties.

The tolerance dimension of CDAT was not found to predict significantly career decision-making difficulties when controlling for the preference and aversion dimensions in one regression model. These findings are in line with those of Xu and Tracey (2015b) who also did not find any relationship 
between tolerance and career decision-making difficulties when controlling for preference and aversion. This finding however deserves further elaboration. One possibility is that what differentiates the tolerance dimension from the other two dimensions in CDAT is the fact that the items seem to tap more into a self-perceived skill (i.e., "I am tolerant of the unpredictability of a career"), compared to the other two dimensions that seem to tap more into motivational and behavioral aspects of CDAT. Therefore, both our findings and those of Xu and Tracey (2015b) could indicate that in particular the motivational and behavioral aspects of CDAT are the main contributors to experienced difficulties in the career decision-making process, and not so much the skill aspect.

The current study provides a more fine-grained picture of the relationship between career-specific ambiguity tolerance, on one hand, and CDSE and career decision-making difficulties, on the other hand. It shows that specifically avoidant behavior regarding complex career information (aversion) and positive cognitive motivational appraisals of complex and novel career information (preference) predict CDSE and career decision-making difficulties. This means that mere tolerance, that is one's perceived ability in handling career informational ambiguity, seems not the most central variable in predicting career decision-making difficulties, which not only has theoretical implications but also has important practical implications.

\section{Practical Implications and Future Directions}

The current research has two related implications for practice. First, our findings can help practitioners like career counselors, teachers, and career managers detect among young individuals the ones who are at risk of experiencing career decision-making difficulties, using the CDAT. Second, our findings can help practitioners to define more specifically the content of interventions aiming at addressing the issue of career decision-making difficulties. For both practical aims, our findings suggest that the most relevant dimensions of CDAT are preference and aversion. This means that in selection and monitoring procedures practitioners should be aware that especially self-reported low enjoyment and liking of career information ambiguity and behavioral avoidance of ambiguous career situations are predictive of experiencing career decision-making difficulties and less low levels of self-perceived tolerance, that is, low self-reported ability in handling career informational ambiguity. Regarding the development of interventions, our findings could be taken as to suggest that interventions might be more effective if they focus (1) more on stimulating the behavioral approach of ambiguous career situations and information and (2) on stimulating and increasing awareness of enjoyment of ambiguity. This could be achieved with take-home exercises and tasks that require from clients exposure to ambiguous career situations and selfreflection exercises, as well as goup discussion activities focused on the positive aspects of such situations. Intervention developers may remind themselves that strengthening directly or reminding clients of one's skills and ability to tolerate career informational ambiguity could be less efficient and therefore may receive less emphasis in interventions. Because our study was conducted among French students, French institutes in charge of career counseling among university students - such as Services Universitaires d'Information et d'Orientation and Bureaux d'Aide à l'Insertion Professionnelle-could especially benefit from our recommendations by including the French CDAT Scale in their annual surveys.

Our study has several limitations. First, both studies are transversal and do not allow causal interpretations. Replicating Study 2 with a longitudinal design could allow testing the causality of the relationship between CDAT and career decision-making difficulties. Second, both studies are based on convenience samples of undergraduate business administration university students from France. Convenience samples are not necessarily detrimental to the validity of studies as noted by Highhouse and Gillespie (2009), but further research could aim at replicating our studies in nonuniversity student populations to investigate the generalizability of our findings. Note that 
our results may also not generalize well to all French-speaking populations. Although French grammar and vocabulary are relatively stable across countries, it is possible that some expressions will require some minor adaptation when using the CDAT Scale in other French-speaking countries than France. Future research could investigate the validity of the French CDAT in other French-speaking countries.

In conclusion, our results enhance our understanding of CDAT. Our study provides researchers and counselors with a psychometrically valid scale to assess CDAT in French-speaking populations. Moreover, our study provides evidence in favor of SCCT (Lent \& Brown, 2013; Lent et al., 1994) by showing that CDAT predicts career decision-making difficulties through career decision selfefficacy.

\section{Declaration of Conflicting Interests}

The author(s) declared no potential conflicts of interest with respect to the research, authorship, and/or publication of this article.

\section{Funding}

The author(s) received no financial support for the research, authorship, and/or publication of this article.

\section{References}

Bandura, A. (1977). Self-efficacy: Toward a unifying theory of behavioral change. Psychological Review, 84, 191-215. doi:10.1037/0033-295X.84.2.191

Betz, N. E., Klein, K. L., \& Taylor, K. M. (1996). Evaluation of a short form of the Career Decision-Making Self-Efficacy Scale. Journal of Career Assessment, 4, 47-57. doi:10.1177/106907279600400103

Betz, N. E., \& Voyten, K. K. (1997). Efficacy and outcome expectations influence career exploration and decidedness. The Career Development Quarterly, 46, 179-189. doi:10.1002/j.2161-0045.1997.tb01004.x

Budner, S. (1962). Intolerance of ambiguity as a personality variable. Journal of Personality, 30, 29-50. doi:10. 1111/j.1467-6494.1962.tb02303.x

Burnham, K. P., \& Anderson, D. R. (2002). Model selection and multimodel inference: A practical informationtheoretic approach. New York, NY: Springer Science \& Business Media. doi:10.4135/9781848608368.n7

Byrne, B. M. (2013). Structural equation modeling with LISREL, PRELIS, and SIMPLIS: Basic concepts, applications, and programming. New York: Psychology Press.

Choi, B. Y., Park, H., Yang, E., Lee, S. K., Lee, Y., \& Lee, S. M. (2012). Understanding career decision selfefficacy: A meta-analytic approach. Journal of Career Development, 39, 443-460. doi:10.1177/ 0894845311398042

Crites, J. O. (1978). Career maturity inventory. Monterey, CA: McGraw Hill.

Furnham, A., \& Marks, J., \& others. (2013). Tolerance of ambiguity: A review of the recent literature. Psychology, 4, 717. doi:10.4236/psych.2013.49102

Gati, I., Krausz, M., \& Osipow, S. H. (1996). A taxonomy of difficulties in career decision making. Journal of Counseling Psychology, 43, 510-526. doi:10.1037/0022-0167.43.4.510

Gaudron, J.-P. (2013). L'échelle des sentiments d'auto-efficacité aux décisions de carrière-forme courte: Une adaptation française pour lycéens. L'orientation Scolaire et Professionnelle, 42. doi:10.4000/osp.4108

Herman, J. L., Stevens, M. J., Bird, A., Mendenhall, M., \& Oddou, G. (2010). The tolerance for ambiguity scale: Towards a more refined measure for international management research. International Journal of Intercultural Relations, 34, 58-65. doi:10.1016/j.jintrel.2009.09.004

Highhouse, S., \& Gillespie, J. Z. (2009). Do samples really matter that much? In Statistical and methodological myths and urban legends: Doctrine, verity and fable in the organizational and social sciences. A. Charles, E. Lance, B. Robert, \& J. Vandenberg (Eds.), (pp. 247-265). New York, NY: Routledge.

Hofstede, G. H., \& Hofstede, G. (2001). Culture's consequences: Comparing values, behaviors, institutions and organizations across nations. Thousand Oaks, CA: Sage. 
Johnston, C. S., Broonen, J.-P., Stauffer, S. D., Hamtiaux, A., Pouyaud, J., Zecca, G., .. Rossier, J. (2013). Validation of an adapted French form of the Career Adapt-Abilities Scale in four francophone countries. Journal of Vocational Behavior, 83, 1-10. doi:10.1016/j.jvb.2013.02.002

Lent, R. W., \& Brown, S. D. (2013). Social cognitive model of career self-management: Toward a unifying view of adaptive career behavior across the life span. Journal of Counseling Psychology, 60, 557. doi:10. 1037/a0033446

Lent, R. W., Brown, S. D., \& Hackett, G. (1994). Toward a unifying social cognitive theory of career and academic interest, choice, and performance. Journal of Vocational Behavior, 45, 79-122. doi:10.1006/jvbe. 1994.1027

Massoudi, K., Masdonati, J., Clot-Siegrist, E., Franz, S., \& Rossier, J. (2008). Assessing the effects of career counseling: The influence of working alliance and individual characteristics. Pratiques Psychologiques, 14, 117-136. doi:10.1016/j.prps.2007.11.010

McLain, D. L. (1993). The MSTAT-I: A new measure of an individual's tolerance for ambiguity. Educational and Psychological Measurement, 53, 183-189. doi:10.1177/0013164493053001020

McLain, D. L. (2009). Evidence of the properties of an ambiguity tolerance measure: The Multiple Stimulus Types Ambiguity Tolerance Scale-II (MSTAT-II). Psychological Reports, 105, 975-988. doi:10.2466/PR0. 105.3.975-988

Muthen, B., \& Kaplan, D. (1992). A comparison of some methodologies for the factor analysis of non-normal Likert variables: A note on the size of the model. British Journal of Mathematical and Statistical Psychology, 45, 19-30. doi:10.1111/j.2044-8317.1992.tb00975.x

$\mathrm{Ng}$, D. (2013). Seeing through the fog of ambiguity: Entrepreneurial judgments under decision settings of complexity. Human Systems Management, 32, 57-66.

Osipow, S. H., \& Gati, I. (1998). Construct and concurrent validity of the Career Decision-Making Difficulties Questionnaire. Journal of Career Assessment, 6, 347-364. doi:10.1177/106907279800600305

Rosseel, Y. (2012). Lavaan: An R package for structural equation modeling. Journal of Statistical Software, 48, $1-36$.

Savickas, M. L., \& Porfeli, E. J. (2012). Career Adapt-Abilities Scale: Construction, reliability, and measurement equivalence across 13 countries. Journal of Vocational Behavior, 80, 661-673. doi:10.1016/j.jvb. 2012.01.011

Schreiber, J. B., Nora, A., Stage, F. K., Barlow, E. A., \& King, J. (2006). Reporting structural equation modeling and confirmatory factor analysis results: A review. The Journal of Educational Research, 99, 323-338. doi:10.3200/JOER.99.6.323-338

Schumacker, R. E., \& Lomax, R. G. (2004). A beginner's guide to structural equation modeling. New York, NY: Psychology Press. doi:10.1111/j.1751-5823.2011.00149.13.x

Storme, M., \& Celik, P. (2017). Career exploration and career decision-making difficulties: The moderating role of creative self-efficacy. Journal of Career Assessment. doi:10.1177/1069072717714540

Willner, T., Gati, I., \& Guan, Y. (2015). Career decision-making profiles and career decision-making difficulties: A cross-cultural comparison among US, Israeli, and Chinese samples. Journal of Vocational Behavior, 88, 143-153. doi:10.1016/j.jvb.2015.03.007

Xu, H., Hou, Z.-J., Tracey, T. J., \& Zhang, X. (2016). Variations of Career Decision Ambiguity Tolerance between china and the United States and between high school and college. Journal of Vocational Behavior, 93, 120-128. doi:10.1016/j.jvb.2016.01.007

$\mathrm{Xu}, \mathrm{H} .$, \& Tracey, T. J. (2014). The role of ambiguity tolerance in career decision making. Journal of Vocational Behavior, 85, 18-26. doi:10.1016/j.jvb.2014.04.001

$\mathrm{Xu}, \mathrm{H} .$, \& Tracey, T. J. (2015a). Ambiguity tolerance with career indecision: An examination of the mediation effect of career decision-making self-efficacy. Journal of Career Assessment, 23, 519-532. doi:10.1177/ 1069072714553073

Xu, H., \& Tracey, T. J. (2015b). Career Decision Ambiguity Tolerance Scale: Construction and initial validations. Journal of Vocational Behavior, 88, 1-9. doi:10.1016/j.jvb.2015.01.006 